\title{
Diagnosis of death guidelines for South Africa - timely and necessary
}

The publication of the multi-society-endorsed South African (SA) Brain Death Guidelines in this issue of the SAJCC are both comprehensive and well timed. ${ }^{[1]}$

Firstly, the document makes the important distinction between circulatory and brain death. This is pertinent in the times we are living in. The current COVID-19 pandemic has led to the need for many difficult decisions around end-of-life care from those working in intensive care. The recent publication of a series detailing the apparent futility of cardiopulmonary resuscitation of COVID-positive patients is an example of such stressors, and their consequences. ${ }^{[2]}$ Moreover, many of these patients were not brain-dead, making the decisions all the more taxing on the emotions of caregivers. The issues around futility or nonbeneficial therapy and the ethical dilemmas around withdrawal of such treatment evokes much emotion as well as legal discussion. ${ }^{[3,4]}$

The current guideline is comprehensive in that while it addresses in detail the diagnosis process for brain death, it additionally defines and addresses clinical determination of circulatory death, a far more common clinical scenario that is often the task of the junior staff on duty in our public facilities. Furthermore, the document discusses these matters in both adults and children, highlighting the exclusions that apply. ${ }^{[1]}$

This emotional burden and the often irrational fears around the concept of brain death make the publication of this document useful for clinical decision-making, and the guidelines also cover the medicolegal aspects well. Of more significance is the fact that they are not just the work of one individual reviewing the literature - a Delphi methodology and a multi-society approach was used to ensure that the concerns of all parties were addressed, and that the best-practice concepts were agreed upon.

Why focus on 'brain death'? Simply put, if the testing for brain death is not correctly done, not only will potentially salvageable patients be missed, resulting in unnecessary death, but organ procurement and transplant programmes will become mistrusted or defunct. Also, when it comes to the testing of brain death, there is much confusion when reading international guidelines as to who should perform the tests. In the SA context, there has been much misinformation, including the suggestion that a neurologist or neurosurgeon must be present; however, this is not the case. These views were probably influenced by international documents that advocate this ${ }^{[5]}$ In SA, any two doctors can perform the tests, as long as both are fully registered for independent practice and at least one has 5 or more years' experience as a registered practitioner, and provided neither is part of the transplant team.

The testing process is outlined in detail, specifically mentioning the prerequisites prior to brain-death assessment, such that confounding variables are suitably addressed. Importantly, the use of 'sternal rub' as a pain stimulus and the 'doll's eye' reflex are no longer recommended. This has important implications for our emergency medical services colleagues, who have both these tests as part of their criteria for diagnosis of death (personal knowledge of Declaration of Death form).

The performance of the apnoea test and the differences in the technicalities in children and patients on extracorporeal membrane oxygenation (ECMO) are clearly presented. Finally, the role for ancillary testing and the options for such testing are elucidated.
The main reason brain-death testing is carried out is for potential or actual organ procurement, as mentioned above, along with the need to withdraw treatment in cases of non-beneficial therapy. The need for organs in SA is huge - there are around 5000 patients awaiting kidney and liver transplants alone, not to mention cornea, skin and bone grafts, among other organs. ${ }^{[6,7]}$

There are a number of ethical issues around the brain-dead patient, particularly while awaiting confirmation of brain death. Social justice in the public sector may demand that accommodation of such patients be deferred in place of a patient needing an intensive care unit bed who is imminently salvageable, thus precluding formal brain-death testing and organ donation. In the private sector this may be less of an issue, such that transferring the body to the private sector for accommodation is a consideration, so long as organ-sharing agreements are in place. ${ }^{[6]}$ Additionally, there appears to be some mistrust of the biomedical system by sectors of the public after the 'kidneygate' saga in 2001. ${ }^{[7]}$ Etheredge also mentions the problem of the need for final family consent, as the family can overrule an expressed wish from a family member to become a donor - donors are lost while awaiting such permission or when the family denies donation. ${ }^{[7]}$ This view is endorsed by Slabbert, who explains that there is no national waiting list (or registry), nor is organ transplantation a national priority. ${ }^{[8]}$ This lack of priority is associated with a massive dialysis workload, and with many patients being denied access to dialysis. ${ }^{[9]}$

Finally, it is important that the criteria for circulatory death have been discussed in detail in the new guidelines. ${ }^{[1]}$ This is because the possibility of so-called deceased cardiac donor is being explored more commonly in SA, particularly in the context of non-brain-dead traumatic brain injury cases who are facing therapy withdrawal. The family can consent to donation and once circulatory death is declared, the transplant team have around 30 minutes to harvest the vulnerable kidneys and liver. Other organs (cornea, skin and bone) may be harvested later with no undue effect. ${ }^{[6]}$

In conclusion, the new SA guidelines for the determination of death hold important educational and practical implications for the practice of medicine, therapy withdrawal for non-beneficial treatments and organ procurement in SA.

T C Hardcastle, MMed (Chir), FCS (SA), Trauma (HPCSA), PhD Trauma Service, Inkosi Albert Luthuli Central Hospital and Department of Surgery, Nelson R Mandela School of Medicine, University of KwaZulu-Natal, Congella, South Africa

hardcastle@ukzn.ac.za

South Afr J Crit Care 2021:37(1):6-7. https://doi.org/10.7196/SAJCC.2021.v37i1.485

1. Critical Care Society of South Africa. South African guidelines on the determination of death South Afr J Crit Care 2021:37(1b):41-54. https://doi.org/10.7196/SAJCC.2021.v37ilb.466

2. Shah $\mathrm{P}, \mathrm{Smith} \mathrm{H}$, Olarewaju A, et al. Is cardiopulmonary resuscitation futile in coronavirus disease 2019 patients experiencing in-hospital cardiac arrest? Crit Care Med 2021;49(2):201-208. https:// doi.org/10.1097/CCM.0000000000004736

3. McQuoid-Mason DJ. Withholding or withdrawing treatment and palliative treatment hastening death: The real reason why doctors are not held liable for murder. S Afr Med J 2014;104(2):102-103. https://doi.org/10.7196/SAMJ.7405

4. Muckart DJJ, Gopalan D, Hardcastle T, Hodgson E. Palliative care: Definition of euthanasia. S Afr Med J 2014;104(4):259-260. https://doi.org/10:7196/samj.8016

5. Wijdicks EFM. Critical synopsis and key questions in brain death determination. Intensive Care Med 2019;45:306-309. https://doi.org/10.1007/s00134-019-05549-6 
6. Muller E. Organ donation and transplantation in South Africa - an update. Cont Med Edu 2013;31(6):220-222. http://www.cmej.org.za/index.php/cmej/article/view/2764/3004

7. Etheredge H. The complex reasons for South Africa's organ donor shortage. https://www.wits. ac.za/news/latest-news/opinion/2019/2019-01/the-complex-reasons-for-south-africas-organdonor-shortage.html (accessed 27 January 2021).
8. Van der Merwe C. SA's shortage of organs for transplant affects thousands. https://www.unisa. ac.za/sites/corporate/default/Research-\&-Innovation/News-\&-events/Articles/SA\%27s-shortageof-organs-for-transplant-affects-thousands (accessed 27 January 2021).

9. Herrmannsen K. Kidney donor shortage fuels dialysis scarcity. https://health-e.org.za/2015/09/01/ kidney-donor-shortage-fuels-dialysis-scarcity/ (accessed 27 January 2021). 